Hammersley-Fletcher, Linda, Clarke,

Matthew ORCID: https://orcid.org/0000-0003-4693-248X and McManus, Vanessa (2017) Agonistic democracy and passionate professional development in teacher-leaders. Cambridge Journal of Education.

Downloaded from: http://ray.yorksj.ac.uk/id/eprint/2423/

The version presented here may differ from the published version or version of record. If you intend to cite from the work you are advised to consult the publisher's version: http://dx.doi.org/10.1080/0305764X.2017.1378312

Research at York St John (RaY) is an institutional repository. It supports the principles of open access by making the research outputs of the University available in digital form. Copyright of the items stored in RaY reside with the authors and/or other copyright owners. Users may access full text items free of charge, and may download a copy for private study or non-commercial research. For further reuse terms, see licence terms governing individual outputs. Institutional Repository Policy Statement

\title{
RaY
}

Research at the University of York St John

For more information please contact RaY at ray@yorksj.ac.uk 
Thank you very much for the opportunity to review the revised version of "Agonistic democracy and passionate professional development in teacher-leaders". This paper looks at the experiences of teachers engaged in research in their schools and how these can be considered as moments of democratic potential. In this, the author(s) develop a notion of democracy as an essentially agonistic form, as outlined by various theorists such as Nietzsche, Arendt and Foucault (p.5). The thesis of the paper is that when teachers engage in research in their schools and classrooms that is oriented towards their students and peers, opportunities for democratic struggle emerge.

There are a number of important points that the paper makes. First, the paper uses an almost historiographical (or perhaps genealogical in keeping with the Nietzsche/Foucault referenced later) analysis of the emergence of teacher/practitioner research from Lewin to Stenhouse (pp.2-3) before arguing that the current politics of teaching, centring as they do around accountability and performativity, have returned the instrumental conditions (simplistic calls for evidence, naïve faith in RCTs etc) that Stenhouse et al were so critical of in the 1970s. Overall, this analysis was well done, the section made compelling points and neatly diagnosed some of the preconditions for the return of this particular problematic. The point, as argued on pp.4-7, is that this is a problem for democracy, a shutting down of the possibilities for struggle. I did wonder, however, if the authors intended to imply (on p.2) that part of the reason the dismantling of Stenhouse's practitioner inquiry was an overextension of the possibilities by Kemmis et al. This point may need to be nuanced.

The section on democracy in general, and agonistic democracy specifically, was a pleasure to read. However, the leap on p.6 from agonistic democracy to Appadurai's deep democracy was unconvincing, inasmuch as it seems to promote a highly individualistic understanding of democracy at odds with the idea of the demos outlined by theorists mentioned before such as Ranciere. One again, I just think this transition needs to be handled a little more carefully. The methods section has been greatly improved in this revised version, and it is much easier to follow the claim for agonistic democracy through the methods and results. Powerful voices are heard, and their desire for new possibilities outside RCTs and learnification is palpable.

My only other suggestion is that the conclusion seems to end rather abruptly, it perhaps needs an additional paragraph tying all of these important insights up into key takeaways in light of the thesis and contexts for the reader. I look forward to seeing this published.

\section{Agonistic democracy and passionate professional development in teacher-}

\section{leaders}

\section{Hammersley-Fletcher ${ }^{\mathrm{a} *}$; M. Clarke ${ }^{\mathrm{b}}$ and V. McManus ${ }^{\mathrm{c}}$}

${ }^{a}$ Faculty of Education, Manchester Metropolitan University, Manchester, Uk;

${ }^{b}$ Faculty of Education, York St. John University, York, UK ${ }^{c}$ Gatley Primary School, Stockport, UK

l.hammersley-fletcher@mmu.ac.uk*corresponding author; m.clarke@yorksj.ac.uk; vmcmanus@gatleyprimary.com 
Linda Hammersley-Fletcher is a Reader in Educational Leadership and Management at Manchester Metropolitan University. Her work engages in the complexities of holding onto educatively driven values and philosophies under circumstances where market-based initiatives often appear to act in tension with such ideals. Linda is engaged on a range of activities within schools that are challenging the boundaries of educational convention in order to emphasize creative and school-led innovation.

Matthew Clarke is Chair Professor of Education at York St John University. His work addresses the intersections of politics and policy in education, particularly in relation to the work of teachers in the neoliberal era. Recent books include Education Policy and Contemporary Theory (Routledge; co-edited with Kalervo N. Gulson and Eva Bendix Petersen), while forthcoming books include Teacher Education and the Political (Routledge; co-authored with Anne Phelan).

Vanessa McManus is an Associate Headteacher and a Specialist Leader in Education at Gatley Teaching School. She has led on research initiatives on both a regional and national scale. The main focus of her work in this area is to develop the role of teachers as researchers and through this co-construct innovative approaches to learning and school development. Vanessa is driving this research focus as an ideal professional development strategy, challenging the more conventional forms of CPD that school's have access to. 


\section{Agonistic democracy and passionate professional development in teacher-leaders}

Politicians and policy makers in education routinely proclaim the centrality of schools and teachers in sustaining and consolidating democracy and democratic society. This article offers an account of teachers engaged in research in their schools and classrooms, with peers and students, in order to highlight the democratic potential of this engagement. In order to do so, it draws on an agonistic account of democracy that is distinct from more familiar liberal or procedural versions. Such an account is characterised by an emphasis on the values of constitutive pluralism, robust contestation and enduring tragedy, where the latter entails recognition of the ineliminable nature of (political) conflict and the inevitability of loss in human life. The teachers involved in our research demonstrated capacities which we argue reflect an agonistic democratic ethos, including: developing the confidence to assume intellectual leadership by asking questions and eliciting and engaging plural perspectives in relation to these questions; engagement in the cut and thrust of research without the expectation of finding any final or perfect solutions and; an acceptance of difference and disagreement as constitutive and constructive elements in rethinking areas of policy and practice. Developing and encouraging these capacities, we argue, is important in an increasingly authoritarian policy context which threatens the vital links between democracy and education highlighted by Dewey a century ago.

Keywords: educational democracy; teacher research; teacher development; teacher empowerment; agonistic democracy 


\section{Introduction}

Politicians and policy makers in education routinely proclaim the centrality of schools and teachers in sustaining and consolidating democracy and democratic society. Thus, for instance, the UK Government's 2016 White Paper, Educational Excellence Everywhere, asserted that "schools and other education providers have an important role to play in promoting the fundamental British values of democracy” (Department for Education (DfE), 2016, p. 97). However - and setting aside the contentious claim that democracy is in some way a 'British', rather than a universal, value - it is important to note that the relationship between education and democracy is nothing if not fraught with difficulty. Some commentators (e.g. Parker, 1996) see schools in Deweyan fashion, as, at least potential, laboratories for democratic society, whilst others adopt a more pessimistic view, seeing schools as anti-democratic agents of capitalist reproduction and socio-political repression (e.g. Bowles \& Gintis, 1976) or at best very unlikely starting points for social reform (Blacker, 2013).

This article does not seek to settle this question - were that even possible - but rather offers an account of teachers engaged in research in their schools and classrooms, with peers and students, in order to highlight the democratic potential of this engagement. In order to do so, it draws on an agonistic account of democracy that needs to be distinguished from more familiar liberal or procedural versions (Wenman, 2013). Such an account is characterised by an emphasis on the values of constitutive pluralism, robust contestation and enduring tragedy, where the latter entails recognition of the ineliminable nature of (political) conflict and the inevitability of losses, alongside any wins, accruing from any choice or decision. This account is explored in greater detail in a later section below; but first we contextualize the research reported by reviewing the links between teachers, research and democracy that have been asserted by thinkers since the mid-twentieth century. We also note the threat to these links posed by developments in education policy in recent years.

\section{Teachers-as-researchers and democratisation}

Teacher research, as a form of practitioner research, is often traced back to the work and ideas of Kurt Lewin (1946). In particular, Lewin's research in factories in the USA in the late 1930s and 1940s demonstrated the superiority of democratic consultation over authoritarian coercion in terms of efficiency and productivity, as 
well as on ethical grounds (Adelman, 1993). Lewin's ideas sought to promote worker participation and self-management, and were taken up and reworked in the UK education context in the 1970s by Lawrence Stenhouse, John Elliot and others, specifically in relation to the work of teachers (Hammersley, 2004). Stenhouse was a firm proponent of teachers engaging in self-critical enquiry using systematic approaches to unpack and interrogate approaches to teaching and learning (Stenhouse, 1981) and was convinced that a good learning experience for students could not be pre-packaged as prescribed curricula (Stenhouse, 1975). In stark contrast to dominant thinking since his death in 1982, he passionately believed that worthwhile teaching should lead to outcomes that were unpredictable and that students should be facilitated in thinking in new and unexpected ways. Rejecting instrumental orientations to schooling, Stenhouse insisted that "education is learning in the context of a search for truth. Truth cannot be defined by the state even through democratic processes - close control of curricula and teaching in schools is to be likened to the totalitarian control of art” (Stenhouse, 1988, p. 44). For Stenhouse and colleagues, the democratic character of teacher research was bound to its inherently participatory, deliberatory and open-ended character. In subsequent decades, proponents of teacher research built upon the democratic claims made in its name by arguing for teacher research as a vehicle for wider social and political transformation (e.g. Atweh, Kemmis, \& Weeks, 1998; Carr \& Kemmis, 1986). These contributions recognise that for teachers the time spent in school and the intellectual and emotional demands of their work mean that their practice often comprises a fundamentally important component of their identities, which in turn highlights the significance of identifying spaces of agency within the work setting (see also Dejours \& Deranty, 2010).

Since the 1980s, education, schools and teachers have been subject to the 'policy pandemic' of neoliberal reform (Vidovich, 2009). Legitimated by discourses of standards and accountability and underpinned by political and media anxiety about educational quality and economic competitiveness, teachers and schools have lost much of their control over the what and how of teaching, to the point where some have argued that the profession has been reduced to the pedagogical equivalent of painting by numbers (Taubman, 2009). Specifically, teaching in the UK and other global contexts, such as Australia and the USA, has been subject to detailed state control of curriculum content alongside increasingly prescriptive strictures regarding pedagogy, 
operationalized through mandated professional teacher standards and teacher education curricula and enforced through punitive inspection regimes (Clarke \& Moore, 2013). The consequence has been the development of cultures of audit and risk management at the expense of a culture of inquiry (Thompson \& Cook, 2013), the promotion of compliance and the erosion of professional autonomy (Groundwater-Smith \& Mockler, 2009; Loh \& Hu, 2014) and the pervasive presence of bureaucratic and technocratic, rather than democratic or relational, cultures of accountability (Ball, 2016; Biesta, 2010; Gipps, 2005; Moncrieffe, 2011). As a result, pressures on schools and school leaders to 'raise standards' and 'achieve results' have significantly increased, with teachers held accountable for the future wellbeing and economic security of the nation (Larsen, 2010), whilst their scope for exercising professional autonomy and democratic agency in relation to their practice has dramatically diminished under the increasing authoritarianism of neoliberal policy regimes.

This increase in performative pressure has in turn fuelled renewed calls for teaching to be grounded in 'evidence'. For example, recent government policy documents in the UK, such as the Carter review of initial teacher training and the White Paper, Educational excellence everywhere, exhort teachers to engage with and ground their practice in 'research evidence' (DfE, 2015, 2016). Yet alongside this insistence that research should inform teaching practices, doubts have been raised regarding the extent to which teachers have the capacity, the resources, the knowledge or even the inclination to locate, utilise or conduct research effectively (Cain, 2016; Dagenais et al., 2012; Williams \& Coles, 2007). This debate comes on top of critiques of education research as overly theoretical, inappropriate in its methods and hence largely ineffectual (e.g. Tooley \& Darby, 1998; Woodhead, 1998; see also DfE, 2016). This is compounded by subsequent criticism that education research needs to learn from, and model itself on, the research practices of other professions, such as the use of the randomised control trials in medicine (e.g. Goldacre, 2013). Such critiques have been eagerly seized upon by policy makers, the media and politicians, whose vision of research is often narrowly scientific (Lather, 2004). Whilst others (e.g. MacLure, 2005; Hammersley, 2013; Furedi, 2013) have questioned the applicability of models such as the medical - which assume people are in deficit (sick) and need to be fixed (cured) to education. We would argue that there are dangers in prioritising particular forms of evidence over others (Nutley et al., 2013), however, the larger point here involves 
consideration of what the subjection of education research to the scrutiny and judgement of those from outside the field tells us about the standing, and the positioning, of education. Moreover, who has the right to determine questions of legitimacy in relation to what we might describe as the educational research imagination? These are fundamentally political questions - which brings us to the question of democracy.

\section{Thinking through democracy}

Democracy is an ambiguous and disputed, if also revered and celebrated, term; but at its core it signifies "the aspiration that the people, and not something else, order and regulate their common life through ruling themselves together” (Brown, 2015, p. 202). Many of the leaders of our democratic systems, pointing to regular 'free and fair' elections and established parliamentary processes as evidence for their case that democracy is alive and well. In so doing they locate themselves in the AngloAmerican tradition of liberal or deliberative democracy. But it could be argued that democratic values have been eroded in recent years in Western societies at the expense of hierarchy and control. Specifically, a number of commentators, most famously Noam Chomsky (Herman \& Chomsky, 1988), but going back as least as far as Walter Lippmann's writings of the 1920s and represented most recently by Owen Jones (2015), have highlighted the way elites use the mass media to manufacture consent among the population. For these critics, a real democracy would be one that included rather than excluded ordinary people, particularly marginal or excluded groups, and enabled them to participate in the political decision-making and in related economic decisions.

Highlighting the absence of such conditions, some have described our current era in terms of 'post democracy', characterized by an increase in the volume of democratic rhetoric alongside a series of assaults on the twin pillars of democratic society, equality and freedom (Crouch, 2004). In this sense, democracy seems to have been usurped by post-democratic and non-democratic forces (Stavrakakis, 2007, p. 256), just as true politics - in the sense of antagonistic debate between genuinely opposed and distinct options - has been 'disenchanted' by economics with competitiveness in terms of wealth creation as the overriding criteria by which any political program is now judged (Davies, 2014). Hence, neoliberalism has conducted a 'stealth 
revolution', replacing homo politicus with homo oeconomicus as public deliberation is displaced by management (Brown, 2015).

Thus, assumptions, logics and practices drawn from the worlds of business management have colonized almost all aspects of life, including education; and democratic politics has become reduced to abstract rights, formal legalism and attempts to occupy a mythical 'center ground' of 'middle England'. This is the utilitarian, pragmatist ethic, which deems radical change unrealistic. This liberal or procedural model reduces democracy to regular elections, popular representation and the protection of certain freedoms. In this paper, we draw on agonistic models of democracy (e.g. Connolly, 1995, 2002, 2004; Honig, 2001; Mouffe, 2000). Reaching back to the Ancient Greeks and coming to contemporary political theory via Nietzsche, Arendt and Foucault amongst others, the concept of agõn refers to the notion of struggle. This notion has been picked up by contemporary theorists, such as William Connolly, Bonnie Honig and Chantal Mouffe, seeking an alternative to the notions of rational consensus and deliberation associated with liberal democracy and wanting to highlight the inevitability of conflict in politics (Schaap, 2015). Of course, the boundaries of agonistic democracy are not set in stone and are a matter of contestation. For instance, Jacques Rancière is considered to be a key agonistic democratic theorist by some (e.g. Schapp, 2009), whereas for others his emphasis on the revolutionary moment of politics at the expense of more quotidian practices of democratic augmentation mean he is a radical, rather than an agonistic, democratic thinker (e.g. Wenman, 2013).

In contrast to the procedural or liberal model, agonistic democracy's theorists embrace the insights of continental thought, including ideas associated with poststructuralism such as the co-constitution of discourse and practice, the ultimate indeterminacy of meaning and the reliance of any category on that which it would exclude. Embracing these insights, agonistic democrats argue that meaningful democratic practice requires recognition of: a) the need to involve a plurality of voices; b) the inevitably tragic nature of life grounded in acknowledgement of human finitude and fallibility which entails that any choice or decision always comes at some cost, bringing losses alongside any gains and; c) the value of contestation and dissensus (Wenman, 2013). Agonistic democrats are hence alive to the disavowals of 
violence and denials of power relations that lurk within assertions of unity and consensus; they are attuned to "the sphere of possibility rather than necessity" (Fielding, 2012, p. 681) though they know that change often comes at significant personal and social cost. As a result, for agonists democracy is a far more vital matter than is often portrayed. In political theorist, John Keane’s words, "when democracy takes hold of people's lives, it gives them a glimpse of the contingency of things. They are injected with the feeling that the world can be other than it is - that situations can be countered, outcomes altered, people's lives changed through individual and collective action” (Keane, 2009, p. 853).

For us, what Arjun Appadurai, describes as ‘deep democracy’, comprising a space where individuals come together "with an eye to building their own capacity to set goals, achieve expertise, share knowledge, and generate commitment” (2006, p. 134) is commensurate with agonistic democracy since both highlight the essential role of the communal in enabling the individual to flourish. In contrast to the top-down version of educational politics promoted and celebrated by the UK government, as well as by other international agents of neoliberal globalisation, this sort of collegial engagement, at least potentially, represents something like a form of 'grassroots globalization’ or 'globalisation from below' (Appadurai, 2001, p. 3).

We view participant-led and curiosity-driven engagement with research by teachers, students and other education stakeholders as embodying, and potentially strengthening, the ethos of agonistic democracy in schools and society. For whereas neoliberalism insists on consensus regarding the largely instrumentally conceived purposes of education, a view of education informed by agonistic democracy is more likely to remain open to possibility and be oriented towards inquiry and the discovery of new knowledge and insights. In contrast to neoliberal education, which is oriented towards the transmission of the already known, an educational politics located within an agonistic-democratic imaginary is likely to engage with the very ontology of possibility (Amsler, 2015).

In this article we consider the ways in which research is utilised in one teaching school alliance (TSA) in ways that echo the ethos of agonistic democracy, where educators are engaged in critically reflexive processes that inform ongoing professional learning 
and development. We begin by introducing the context and approach we have taken to gathering our data. We then move on to discuss the data itself, examining it in light of our discussion of agonistic democracy and considering the ways in which it might facilitate and enhance democratically oriented teacher-leadership.

\section{The research study}

This project arose through collaboration between one Teaching School Alliance (TSA) and a university in the North of England. The intension of the project was to facilitate the developing role of research leader and the growth of the Alliance, including school to school support. Topics covered were open to individual choice and working across schools was also a potential for the identified staff. Initially, this research was designed around randomised control trials (RCTs), with each school nominating researchleaders to undertake a school improvement research project, the results of which could be disseminated both to the school(s) involved and across the wider Alliance; however the teachers rejected RCTs as they felt they unduly limited the scope of their inquiries. A lead teacher advocate instigated this research project, helping to coordinate the academic support provided to the teachers undertaking this work during the academic year 2014-15 and documenting the teachers' research activity and attitudes. It is this engagement with the research journey, rather than pedagogical findings from the specific projects, that forms the focus of this article.

The TSA consisted of nine schools (eight primary and one secondary) representing a variety of socio-economic circumstances and situated in the North West of England. Each of the headteachers of the nine TSA schools were invited to opt in or out of the project. Two schools declined to engage with this process and five schools sustained their participation to the end of the project (wider personal issues had prevented two schools completing the project). Each of the schools engaging in the project identified two research leaders who would then focus a project on an aspect of school improvement that interested them and involve other staff in this activity. Research leads were facilitated to work together either within or across schools with others leads who had similar interests. As a result, five projects were identified. The research leaders also received central support from two of the authors (the lead teacher advocate and an academic researcher). Research leads understood that this approach was an innovation in terms of Alliance activity and that as such their experiences would be 
recorded and their opinions sought.

The data that forms the basis for the current paper were generated through semistructured interviews with one of the members of staff leading each project. Barbour and Schostak (20011:65) state that "the interview is a critical strategy in generating the intersubjective features of the public and private spaces of social life”. We were seeking to understand the impact that undertaking research was having on the teachers engaged in this project. Participants were asked to discuss how they became involved in the project, how they felt at various stages of the project and what they perceived to be the positive and negative aspects of their engagement in this initiative. Data were also generated through written questionnaire responses from the nine headteachers within the TSA (irrespective of their engagement in the project itself). As Anderson et al (2013) state, through the use of open-ended questions headteachers were able to elaborate their thoughts about the project. Data were analysed through utilising a grounded approach involving a dialectic between data analysis and theory as part of an emergent method (Charmaz, 2008). Thus, notions of democracy was not a topic initially discussed with the teachers engaged in this project but the analysis indicated that engagement in the project was having unforeseen impacts that could be characterised as building on teacher voice and agonistic democratic engagement. Moreover, as the paper developed the findings were reported back to the teachers engaged in these projects for their comments and suggestions.

BERA (2011) ethical guidelines were adhered to throughout the study and University ethical clearance obtained prior to commencement. In addition to consulting with participants with regard to our emergent findings, we used mapping techniques to analyse data and develop themes and foci for further investigation (Buzan and Buzan, 1996), as part of a process of an iterative dialogue with theoretical and research literature. Activity has since continued with all nine schools engaging in the second and third rounds of research activity and enthusiasms for engaging with a broad spectrum of research approaches has developed. It should be noted that all participants are referred to by pseudonym in order to protect their identities. 


\section{Research Findings}

When examining the data we discovered that the stories articulated by the research leads less expressive of the research project they had been running but rather the project was acting as a vehicle for a more significant shift in teacher practices. Their narratives involved themes of leadership, collaboration, confidence, energy and enthusiasm, as well as personal and professional development. Overall, in analysing the data we percieved significant identity shifts in terms of the research leads altered attitudes and changing expectations of themselves and others and, as noted above, teachers came to express doubts about the value of undertaking RCTs in schools. Here therefore, the focus of our discussions of data is around the shifts in research leads perspectives on undertaking research. Specifically, the analysis presents the data in relation to the three core tropes of agonistic democracy outlined above: pluralism; tragedy and; contestation. We should note, however, that whilst we have separated these aspects of agonistic democracy that we saw echoed in the data for analytic purposes, in 'reality' they are far more intertwined and mutually reinforcing than this might suggest.

\section{Recognising a plurality of voices}

Initially many of those engaging in this research saw the project in instrumental terms, as designed to improve aspects of practitioner practice in a fairly 'straightforward' manner. Thus, some of the heads commented that the purpose of the research was to “develop teachers' research skills that will in turn impact upon their practice” (Barbara) or "to help close the gap in attainment of phonics” (Frances), with two further heads not having anything to say about what they saw as the purpose of the project. Thus this was not being seen as a project about voice but one focussed purely on teachers reflecting on their own practice in ways that might aid school improvement. In other words, the question for these heads was what set of numbers were necessary to make this painting complete (Taubman, 2009). In Biesta's (2006, 2013) terms, we might say this focus reflects the colonisation of their thinking about the field of education by the narrowly conceived discourse of 'learning' and its genuflected references to notions of 'achievement', 'standards', 'outcomes' and 'best practice'. Research leads echoed views expressed by the heads in tying the research agenda to shifting classroom practice, albeit through a desire to engage with new ideas and different perspectives. 
In teaching we get into a rut sometimes and forget there are things out there that we can do with the children and it's looking to see what else we can bring to the equation. For me it's looking at other things as well that are going on at the moment. It's reading, it's not just opening a book. It's asking the children what they want, I suppose, and that's a bit of day-to-day research. (research lead Emily)

There was also a desire to maintain and consolidate zones of familiarity, when embarking on this work but as the teacher leads became engaged in their research projects this understanding appeared to extend. For example, initially the selected research leads (who were tasked with working in groups where this was appropriate) appeared to gravitate toward those colleagues with similar experiences and seemed to carry out an informal and covert baseline assessment of each other. However, the open nature of the research topics selected limited the opportunity to do this and the research leads had to negotiate new ways of working with colleagues with whom they had not worked before. The challenge was described in the following way by research lead Katharine.

There were two of us leading my project so we were working collaboratively alongside each other which again was another aspect of challenge, working with someone I had never worked with before or met before the very first planning meeting. We had to actually build that working relationship and to use each other's expertise to be able to get the research project off the ground and moving, and get people on board, making sure that we were both delivering the same message as well.

From this response, we see the recognition that working together involves listening to and adapting planning on the basis of negotiating different voices. Research leaders thus had to find ways of operating to co-construct their work through listening to others views and this, they reflected had clearly had a positive impact on their leadership and negotiation skills. Qualities of facilitation, coaching and consultation were in evidence, which in turn, up skilled the different layers of staff within the 
schools involved and enhanced the likelihood of wider, more dispersed contribution to discussion and debate about matters of common concern.

I'm hoping that my enthusiasm for the [research project] will come through to the other staff as well and getting them to buy into something that feels relevant to that. So it's not 'here is your trial and here's what you're going to do and this is your project and this is it.' It's actually getting them on board in the design of the project that was apparent throughout this process. (Katharine)

Thus, Katharine not only benefitted personally from recognising the importance of alternative voices but was now actively trying to encourage a plurality of voice through opening opportunities for her colleagues to give their opinions. Additionally, because of the involvement of a university, the research leaders had opportunities to develop their understandings by engaging in knowledge produced from a range of sources (Nelson and O’Beirne, 2014), beyond the boundaries of their own school. They valued sharing experiences with others and exposing their own practices, beliefs and ideas to a plurality of other voices and perspectives, something they found both thought provoking and enlivening. Additionally, as their motivation and confidence developed through their engagement with others within and beyond their own school, so too their confidence and ability to voice ideas was enhanced through the sharing and development of new skills and insights in collaboration with others (including working with research academics). "It was a team approach, not looking at developing ourselves in isolation because we knew we would be impacting on other schools” (research lead Louisa).

In this way, research leads were finding that through the medium of engaging in research activity, they were empowered to engage in discussions and then take a more high profile stance in leading change initiatives within their school. They began to feel ownership through co-designing something that would make a significant contribution to school development and have a beneficial effect upon learning; but they also felt empowered and enabled to work strategically with other staff and thereby create a more pluralistic and inclusive (thus democratic) ethos in the school. This activity was therefore giving staff agency in the work place (see for example Dejours and Deranty, 2010). In other words, in order to support a sustainable 
development culture in schools, research practice needs to be not only a vehicle for individual and school improvement, but also a way in which research leads can cooperate to incorporate an enlarged pluralistic circle of voices to bring about systemic school improvement and enhance the democratic ethos within and across schools.

\section{Embracing a tragic perspective}

Much recent education policy seeks to impose control over the inevitable messiness of social processes and to manage risk and uncertainty with severe penalties imposed on those falling foul of expectations. Not surprisingly, uncertainty is not something that these research leaders always embraced as a positive thing and they appeared to (unconsciously) seek and/or impose order on the work they were undertaking. As Thompson and Cook (2013) argued, avoidance of risk has been strong in schools and has operated to block creativity. Working across the alliance and with an academic researcher meant that teachers were being pushed beyond their usual circle of colleagues and having to engage with the personalities and perspectives of others they knew much less about. Where these research leaders were used to being in control and organising their activities within set patterns, engaging in this project suddenly meant that they were confronted with a lack of control in the form of academic input and other unanticipated variables as part of a project with an uncertain and undetermined end point. This shift in the balance between control and creativity amongst these teachers presented a continual challenge for them and the desire to identify structure and guide their own learning is reflected in their comments. The fact that they had to lead and work with colleagues from other schools only added to this tendency:

I soon understood that I would be developing it myself to then go out and lead which I initially thought was quite frightening. (research lead Mary)

...we worked as a team together and also obviously if people are going wrong it's somebody to bounce ideas off. What can I do better and it's that growth that you developed from each other really. (research lead Janie)

The notion that this was a project where you could get it 'wrong' and therefore you gathered strength by sharing ideas, indicated the tension that these research leads are 
used to facing. The open nature of each project caused a degree of anxiety, although this was ameliorated somewhat by the school improvement related agenda, which provided some sense of control over the research process and afforded comfort to the research leads in their planning. Nonetheless, for all there seemed to be a point of realisation that they were engaged in something new and potentially cutting-edge in terms of teacher-researcher practice, requiring them to generate and synthesize knowledge. This shift in their positions forced them to start thinking in new ways about their roles, perhaps signalling the beginnings of a laboratory for democratic processes (Parker, 1996). As Janie went on to say,

I think it's just have a go really and not feel as if you're scared of anything and try it, if it doesn't work it doesn't work, you know, have a go and be as open as possible and reflect on what you find out because you might not find out what you want to, so you don't always get what you want.

So these teacher leads were at one and the same time confronted with their own finitude, whilst also awakened to the possibilities for transcending limits opened up by working as part of something bigger than themselves.

It's maybe a little bit more than we thought it... Right ... But at the same time it's really exciting and was really inspiring and exciting thing to be part of ... (Mary)

This notion of being part of something 'exciting' and 'inspiring' was what facilitated these research leads to stay with the project and work through their discomfort with the unknown, which we identified earlier as part of the inevitably tragic nature of human existence and which so much education policy and practice seeks to manage and contain. Moreover, they were also conscious of having been identified by their head teachers as the people who could lead this initiative forward and they wanted to show that they were worthy of the trust placed in them.

Being asked to lead on a team was a lovely complement for me as well, which was really nice. My head teacher felt that I could do it and it was 
just carrying on developing myself as a leader in school to be honest and my sort of journey will carry on. (Emily)

In this way these research leads were attempting to capture a sense of professional autonomy which much governmental policy making has worked to erode (Loh and $\mathrm{Hu}, 2014)$. Indeed, it is clear from the interviews with these research leaders that many came to embrace the uncertainty that arises from continuous questioning as a means of enhancing and reanimating their professional practice and thus valued their engagement in research for the benefits it brought in such expansive terms:

I think one of the biggest things for me is that it's opened my eyes further to actually what's out there and the world of research within education and how useful it can be. Also in asking questions and being confident to ask those questions and find those answers and although this was quite a large project that, when over time, when you take stock and reflect, I found I do this more and more and more asking the questions and thinking through the process and it could be on a daily basis. (Katharine)

As this suggests, these research leaders were looking for ways to enliven their practices and what became clear was that engaging in research activity had given them a sense of a renewed energy and a growing confidence to embrace risk in order to break free of the shackles of what might conventionally be deemed 'good practice' in the hope of discovering and creating something new. Here we can glimpse the tragic view of life, not as a recipe for disaster, despair and self-defeat, but as a spur to ethical aspiration, albeit without any guarantees of success:

It has enabled us to look at learning in a different way. For us it was about risk taking and being innovative - doing something we'd not done before. (Louisa)

With this came a willingness to develop their own understandings of themselves as leaders in learning, something that seemed to be fuelled by a growing sense of intellectual capability and an enjoyment of talking about practice with colleagues. 
This was something that they felt had benefitted colleagues’ practices too:

She's [teaching assistant colleague] got the confidence to say, 'actually I can do this'. She is going to try and do something different for herself - possibly the teaching route - I don't know but she's gone to educate herself. She feels that she has grown and got more confidence and that's what's come from this, the elements 'I've been given the chance to grow and blossom,' (Emily)

It became apparent that other research leads were facilitating staff development as a consequence of seeing the value of adopting non-routinised approaches to working with other staff. Their reanimated attitude, at once reverent and creative, put colleagues at ease and encouraged them to seek at their own answers.

I suppose, because as a leader quite often you will do a staff meeting and you'll think to yourself 'right ticked off a staff meeting and everybody's going to go off and do it now,' and it's almost like that job’s done and I can move on to the next thing. Whereas the informal coaching meant that it was always fresh in my mind. I was always dropping in. It was always fresh in the mind of the members of staff I was dropping in on, because they weren't doing a staff meeting thinking that's ticked off till the next book scrutiny. (Janie)

This notion that research activity gave you what we might describe as an 'antiroutine' for regular engagement with colleagues, thereby engendering a sense of working as a team on something that transcends each individual's finite contribution was a powerful message across all of the interviews and one that reflects both the pluralistic and the tragic dimensions of agonistic democratic practice.

\section{The value of contestation}

The research leads all reported professional benefits from engaging in this activity and commented upon the ways in which this has informed their understandings of and confidence in leadership practices. Interestingly these comments were not focussed on conventional ideas of impact and may demonstrate a growing recognition that impact 
might be measured in different ways (Fenwick and Farrell, 2012). Moreover, with the additional support of the alliance as a network, their openness to view mistakes as part of the learning journey, as well as their tolerance for ambiguity, uncertainty and disagreement, increased as a consequence of engagement in research activity. It moreover begins to challenge notions that teachers do not have the capacity to research effectively (Cain, 2016). For example research lead Katharine had found problems with the research outcomes but still recognized the value of research activity.

The data that we'd gathered in the middle didn't really tell us anything other than how hard it was to administer a questionnaire that everybody understood. Some children had read it one-way and some children had read it another and their answers didn’t seem to tally.

For many research leads, their concept of knowledge and practice initially involved knowing and delivering the curriculum, rather than uncertain experimentation with the application of existing research or developing and trialling new ideas. Involvement in research projects, however, saw the research leads developing views of knowledge and practice as an essential blend of both routine and improvisation. Meanwhile, though the presence of a perceived 'expert', whether an academic or a colleague in the research team, added complications, it also encouraged and emboldened the research leaders to stand their ground and embrace contestation.

\footnotetext{
Another aspect of managing the team was that we did have someone on the team that was sort of very experienced within the research field which was helpful but an awful lot of the questions that were thrown up there sort of tried to take things in different directions and we had to be quite strong in some areas (Katharine)
}

This tension required the leaders to engage in negotiation in order to handle a variety of opinions and perceived degrees of expertise, so that all feel that they were taken seriously as part of an agonistic - rather than antagonistic - debate. This highlights the importance of sharing expertise across groups of teachers but also to the need for researchers and teachers to be able to speak the same language, so that one group does 
not feel at a disadvantage. As Mary argued “I think everyone’s been there to help each other which has been really good”. Based on these lively conversations between professionals, a deeper dialogue across schools and HEIs can be established, resulting in recognition that the discussion in meetings between schools can be deepened to engage more critically and analytically with the work undertaken as learners as well as leaders (Godfrey, 2014).

It was about having that dialogue at a really deep level and making mistakes and learning from them. It was more about the process even though the outcome was important. (Louisa)

This summarised the feelings expressed by other research leads too, who talked of their personal development and the depth to which they now engaged in selfquestioning and challenging taken-for-granted practices. In other words, there was acceptance of the need for ongoing questioning and critique, that the outcome, though a significant consideration, will never be perfect and that as, if not more important, is the actual process of engaging in research alongside others by asking and addressing questions. This research journey lacks an ultimate destination and will necessarily involve mistakes and wrong turns along the way as Stenhouse (1975) advocated, as well as surfacing and highlighting differences of views and values amongst staff but from an Alliance perspective it has operated to enliven and develop staff. As Janie explained,

I feel a lot more confident now ... I've stood in a large room with lots of people who ... I didn't know so yeah I've grown in confidence to be able to do that.

Head Dorothea also explained that,

discussions in the last two [Headteacher] meetings have been extremely interesting. It would appear that the outcomes have been positive for the individuals and the schools involved.

\section{Conclusion}


What was palpable as a result of these research activities was the development in the energy and enthusiasm of staff and the effects that their passionate research leadership was having on the pupils taught and the environments of the schools where these activities took place, echoing the findings and arguments of others (e.g. Davies \& Brighouse, 2008; Simkins, Maxwell \& Aspinall, 2009). As Janie put it, noting how her engagement in research had brought about a new sense of energy and purpose, "I think it just feels really new and fresh and innovative and not something that everyone is part of and it feels really nice to be involved with something that you feel is almost leading the way”. Moreover, this outcome was tangible to many of the headteachers involved who were not only keen to continue with their school's involvement in research but were keen to expand the circle of those involved. As one head (Frederick) put it, "I was reluctant at the idea last year [the year reported here] because I felt we had more important priorities - having seen extremely positive outcomes for pupils and colleagues I'm now really keen to involve our staff”. Likewise, headteacher Nancy expressed a sense that this research study was acting to develop staff and that "I feel that the research could go from strength to strength and begin to become embedded in the CPD for the future". And head Lydia argued that "I see the research getting wider and stronger and impacting more on practice throughout the alliance". This is significant in the context of recent research suggesting that conflicts with work schedules, cost, absence of incentives and lack of employer support are key obstacles to teachers' participation in continuing professional development in England (OECD, 2016; Sellen, 2016).

This Teaching School Alliance have taken what appears to be a brave step in dedicating time and resources to allow teaching staff to engage in research-based practices. Whilst initially somewhat instrumentally based, this project has developed with all participants and all schools within the alliance developing a growing awareness that the findings of the research projects are of relatively minor importance when compared to the professional benefits for staff. These include: developing the confidence to assume intellectual leadership by asking questions and eliciting and engaging plural perspectives in relation to these questions, thereby enlivening their own and their colleagues' professional practice and identities; engagement in the cut and thrust of research without the expectation of finding any final or perfect solutions and with growing confidence that mistakes are part of the learning journey and not 
disasters and; an acceptance of difference and disagreement as constitutive and constructive elements in rethinking areas of policy and practice.

Significantly, all participants felt that they had learned a lot from undertaking this work and a fresh and larger cohort of teachers have engaged in this process for its second and now third year in practice. Moreover, the strong links developed between the schools and academic research support has proved invaluable for all concerned where all have engaged with the process as a group of peers who can each learn from the others. One of the clear lessons of this journey was the realisation that teachers and their work are increasingly circumscribed and that they are 'encouraged' to follow guidelines that control classrooms, teaching and learning in particular ways. A key challenge in undertaking this research was 'letting go' of some of that control and starting to think about education in ways that freed them as professionals to be more critical and creative in their approaches and thinking - in John Macmurray's terms, to move beyond 'knowing how' and to engage with questions of 'knowing why' (Fielding, 2012, p. 679). Our overall argument is that this change has a democratic ethos at its core and that it echoes the contours of agonistic democracy in its recognition of the value of plurality and contestation.

These experiences lead us to suggest that undertaking such school community-based research activity in alliance with research active university staff, facilitates all involved to develop deeper understandings of the educative journey that will enliven and invigorate practice. A new energy and sense of purpose becomes infectious, thereby engaging the support and contributions of additional staff, thus building a sense of dynamism that is hard to ignore. This is an alliance where the sense of adventure and excitement is palpable. However, in order to facilitate such work those involve need to grapple with loss. In order to gain the benefits of such activity we must 'let go' of a number of things including the familiarity of specific practices, the idea that we have the answers already, the notion that we have control of all outcomes, the notion that we might know best. Letting go of such key parts of practitioner identity and practice can be threatening but by opening up to changes in thinking and practice we become more confident and capable of accepting and dealing with the unexpected and more open to the innovations that make education exciting. 
Whilst we don't believe that there are any 'quick fixes' in education or in wider political life, as authors and participants in this project we have seen the power of participation, whereby relatively small projects, championed by enthusiasts, can make a dramatic difference to practices and identities, not least by 'putting persons back into education' in the face of the objectifying practices and depersonalising language of neoliberal managerialism (Pring, 2012). Participation in such research can be a powerful tool, not just for change, but as evidence that change is indeed possible when teachers work on projects together as colleagues, within and across schools, engaging a range of voices and experiences including those of senior school leaders, students and HEI colleagues. Such participation offers a means of 'countering the poverty of the present' by establishing deliberative and transformative communities of 'democratic fellowship (Fielding, 2012, p. 687 \& p. 690). Adapting our earlier quote from John Keane, we might say, "when research [democracy] takes hold of people's lives, it gives them a glimpse of the contingency of things. They are injected with the feeling that the world can be other than it is - that situations can be countered, outcomes altered, people's lives changed through individual and collective action” (Keane, 2009, p. 853).

\section{References}

Adelman, C. (1993). Kurt Lewin and the origins of action research. Educational Action Research, 1(1), 7-24.

Amsler, S. (2015). The education of radical democracy. London: Routledge.

Andersen, M., Taylor , H., and Logio, K. (2015) Sociology: the essentials. USA: Cengage Learning.

Appadurai, A. (2001). Grassroots globalization and the research imagination. In A. Appadurai (Ed.), Globalization (pp. 1-21). Durham, NC: Duke University Press.

Appadurai, A. (2006). Fear of small numbers: An essay on the geography of anger. Durham, NC: Duke University Press.

Atweh, B., Kemmis, S., \& Weeks, P. (1998). Action research in practice: Partnership for social justice in education. New York: Routledge. 
Ball, S. J. (2016). Neoliberal education? Confronting the slouching beast. Policy Futures in Education, 0(0), 1-14.

Barbour, R. and Schostak, J. (2011) “Stories from the field - interviewing” in Somekh, B. and Lewin, C. (2011) (eds) Theoiry and Methods in Socail Research - second edition London: SAGE

BERA (2011) Ethical Guidelines https://www.bera.ac.uk/researchersresources/resources-for-researchers - accessed May 2016

Biesta, G. (2006). Beyond learning: Democratic education for a human future. Boulder, CO: Paradigm Publishers.

Biesta, G. (2010). Good education in age of measurement: Ethics, politics, democracy. Boulder, CO: Paradigm Publishers.

Biesta, G. (2013). The beautiful risk of education. Boulder, CO: Paradigm Publishers. Blacker, D. (2013). The falling rate of learning and the neoliberal endgame. Winchester: Zero Books.

Bowles, S., \& Gintis, H. (1976). Schooling in capitalist America. New York: Basic Books.

Brown, W. (2015). Undoing the demos: Neoliberalism's stealth revolution. Cambridge, MA: MIT Press.

Buzan, T. and Buzan, B. (1996). The Mind Map Book: How to use radiant thinking to maximise your brain's untapped potential. London: Penguin.

Cain, T. (2016). Denial, opposition, rejection or dissent: Why do teachers contest research evidence? Research papers in education, 1-15.

Carr, W., \& Kemmis, S. (1986). Becoming critical: Educational knowledge and action research Lewes: Falmer Press.

Charmaz, K. (2008). Grounded theory as an emergent method. In S. N. Hesse-Biber \& P. Leavy (Eds.), Handbook of emergent methods (pp. 155-172). New York: Guilford Press.

Clarke, M., \& Moore, A. (2013). Professional standards, teacher identies and an ethics of singularity. Cambridge Journal of Education, 43(4), 487-500.

Crouch, C. (2004). Post-democracy. Cambridge: Polity Press.

Dagenais, C., Lysenko, L., Abrami, P. C., Bernard, R. M., Ramde, J., \& Janosz, M. (2012). Use of research-based information by school practitioners and determinants of use: A review of empirical research. Evidence \& Policy: A Journal of Research, Debate and Practice, 8(3), 285-309.

Davies, B. and Brighouse, T. (2008). Passionate Leadership in Education. London: Sage Publishing. 
Davies, W. (2014). The limits of neoliberalism: Authority, sovereignty and the logic of competition. London: Sage.

Dejours, C. and Deranty, J-P. (2010). The Centrality of Work. Critical Horizons 11(2), 167- 180

Department for Education. (2015). Carter review of initial teacher training. London: HMSO.

Department for Education. (2016). Educational excellence everywhere. UK: HMSO.

Fenwick, T. and Farrell, L. (2012). Introduction: Knowledge mobilization: the new research imperative. In, T. Fenwick and L. Farrell (Eds) 2012. Knowledge Mobilization and Educational Research: Politics, Languages and Responsibilities. London: Routledge, pp. 1- 14.

Fielding, M. (2012). Education as if people matter: John Macmurray, community and the struggle for democracy. Oxford Review of Education, (38)6, pp. 675-692.

Furedi, F. (2013). Keep the Scourge of Scientism out of schools. http://www.spikedonline.com/newsite/article/dont_import_the_scourge_of_scientism_into_scho ols/\#.VglDT 2RVhBd

Gipps, C. (2005). Accountability, testing and the implications for teacher professionalism. In C. Dwyer (Ed.), Measurement and research in the accountability era. New York: Routledge.

Godfrey, D. 2014. Leadership of schools as research-led organisations in the English educational environment: cultivating a research-engaged school culture. Educational Management, Administration \& Leadership, 1-21.

Goldacre, B. (2013). Building evidence into education. London: HMSO.

Groundwater-Smith, S., \& Mockler, N. (2009). Teacher professional learning in an age of compliance: Mind the gap. Dordrecht: Springer.

Hammersley, M. (2004). Action research: a contradiction in terms? Oxford Review of Education, 30(2), 165-181.

Herman, E. S., \& Chomsky, N. (1988). Manufacturing consent: The political economy of the mass media. New York: Pantheon Books.

Jones, O. (2015). The establishment: And how they get away with it. London: Penguin.

Keane, J. (2009). The life and death of democracy. New York: Norton. 
Larsen, M. (2010). Troubling the discourse of teacher centrality: A comparative perspective. Journal of Education Policy, 25(2), 207-231.

Lather, P. (2004). This is your father's paradigm: Government intrusion and the case of qualitative research in education. Qualitative Inquiry, 10(1), 15-34.

Lewin, K. (1946). Action research and minority problems. Journal of Social Issues, 2, 34-46.

Loh, J., \& Hu, G. (2014). Subdued by the system: Neoliberalism and the beginning teacher. Teaching and Teacher Education, 41, 13-21.

MacLure, M. (2005). 'Clarity bordering on stupidity': where's the quality in systematic review? Journal of Education Policy, 20(4), 393-416.

Menter, I. (2016, April 1st). Use, abuse and misuse of research in the education white paper. Times Higher Education. Retrieved from http://timeshighereducation.com/blog-use-misuse-and-abuse-researcheducation-white-paper

Moncrieffe, J. (2011). Relational accountability: Complexities of structural injustice. London: Zed Books.

Nelson, J. and O’Beirne, C. (2014). Using Evidence in the classroom: What works. Berkshire: NFER.

Nutley, S. (2013). Reflections on the mobilisation of education research. In, Levin, B., Qi, J., Edelstein, H. and Sohn, J. (Eds). The impact of research in education: An international perspective. Bristol: The Policy Press.

OECD. (2016). Education at a glance 2016: OECD indicators. Paris: OECD Publishing.

Parker, W. (Ed.) (1996). Educating the democratic mind. New York: SUNY Press.

Pring, R. (2012). Putting persons back into education. Oxford Review of Education, (38)6, pp. 747-760.

Schaap, A. (2015). Introduction. In A. Schaap (Ed.), Law and agonistic politics (pp. 1-15). London: Routledge.

Sellen, P. (2016). Teacher workload and professional development in England's secondary schools: Insights from TALIS. London.

Simkins, T., Maxwell, B. and Aspinwall, K. (2009). Developing the whole-school workforce in England: building cultures of engagement. Professional Development in Education, 35(3), 433-450.

Stavrakakis, Y. (2007). The Lacanian left. Edinburgh: Edinburgh Univesity Press. 
Stenhouse, L. (1975). An Introduction to Curriculum Research and Development. London: Heinemann

Stenhouse, L. (1981) What counts as research? British Journal of Educational Studies 29(2), 103-114.

Stenhouse, L. (1988). Artistry and teaching: The teacher as focus of research and development. Journal of Curriculum and Supervision, 4(1), 43-51.

Taubman, P. (2009). Teaching by numbers: Deconstructing the discourse of standards and accountability in education. New York: Routledge.

Thompson, G., \& Cook, I. (2013). The logics of good teaching in an audit culture: A Deleuzian analysis. Educational Philosophy and Theory, 45(3), 243-258.

Tooley, J., \& Darby, D. (1998). Educational research: A critique: A survey of published educational research. London: Ofsted.

Vidovich, L. (2009). 'You don't fatten the pig by weighing it': Contradictory tensions in the 'policy pandemic' of accountability infecting education. In M. Simons, M. Olssen, \& M. Peters (Eds.), Re-reading education policies: A handbook studying the policy agenda of the 21st century (pp. 549-567). Rotterdam: Sense Publishers.

Wenman, M. (2013). Agonistic democracy: Constituent power in the era of globalisation. Cambridge: Cambridge University Press.

Williams, D. and Coles, L. (2007). Teachers' approaches to finding and using research evidence: An information literacy perspective. Educational Research, 49(2), 185-206.

Woodhead, C. (1998). Academia gone to seed. New Statesman, 20(3), 51-52. 